\title{
O PROGRAMA INSTITUCIONAL DE BOLSAS DE INICIAÇÃO À DOCÊNCIA - PIBID E A VALORIZAÇÃO DA FORMAÇÃO DOCENTE NA UFRN/CAMPUS CENTRAL
}

\author{
Erivania Melo de Morais ${ }^{1}$
}

Elda Silva do Nascimento Melo

\section{RESUMO}

O Programa Institucional de Bolsas de Iniciação à docência - PIBID, foi instituido com a finalidade de fomentar a Iniciação a Docência dos licenciados das Instituições Federais de Educação Superior, permitindo a esses, uma inserção na prática educativa de modo críticoreflexivo. Neste sentido, propomos neste artigo, apresentar o PIBID/UFRN de forma sistemática e refletir acerca de sua contribuição para a valorização da formação docente. Para realizarmos esse exercício de reflexividade, nos reportamos a uma investigação de cunho bibliográfico e documental, que contemplou desde a legislação do PIBID e PIBID/UFRN, nos permitindo dessa forma uma aproximação das suas perspectivas de ação, e também a autores como Boventura Santos (2005); Novoa (2009), Morin (2004) Candau (2013), que nos deram um respaldo teórico para pensar a relevância do PIBID/UFRN na valorização dos licenciandos. Deste modo, podemos apontar brevemente a relevência do programa por possibilitar aos licenciandos a inserção na docência de forma crítica-reflexiva, através de uma tateamento da prática, além da pertinência da formação que é realizada dentro da profissão, aproximando os licenciandos das realidades diversas do contexto da escola publica, ampliando seus pontos de vista e conscientizando-os para a busca de uma educação democrática e de qualidade.

Palavras- chave: PIBID. PIBID/UFRN. Valorização docente. Formação docente.

\section{THE PROGRAMA INSTITUCIONAL DE BOLSA DE INICIAÇÃO À DOCÊNCIA- PIBID AND THE VALORIZATION OF TEACHER TRAINING IN UFRN/CENTRAL CAMPUS}

\begin{abstract}
\footnotetext{
${ }^{1}$ Mestre em Educação(PPGED) e doutoranda do PPGCS/CCHLA, UFRN.

2 Pós-doutora em Educação pela Universidade de Valencia, Espanha.
}

The Programa Institucional de Bolsas de Iniciação à docência - PIBID, was instituted with the purpose of encouraging the Teaching Initiation of the graduates of the Federal Institutions of Higher Education, allowing those, an insertion in educational practice in a critical-reflective way. In this sense, we propose in this article to present the PIBID / UFRN in a systematic way and reflect on its contribution to the valorization of teacher education. In order to carry out this exercise of reflexivity, we are referring to an investigation of a bibliographic and documentary 
nature, which included the legislation of PIBID and PIBID/UFRN, we allowing us to approximate their perspectives of action, as well as to authors such as Boventura Santos (2005); Nóvoa (2009), Morin (2004) Candau (2013), Who gave us theoretical support to think about the relevance of PIBID / UFRN in the valuation of graduates. Thus, we can briefly point out the relevance of the program by enabling the graduates to insert in teaching in a criticalreflective way, through a groping of the practice, besides the pertinence of the formation that is realized within the profession, approaching the licenciandos of the diverse realities of the context of the public school, amplifying their points of view and raising them to the search of a democratic education and of quality.

Keywords: PIBID. PIBID / UFRN. Teacher appreciation. Teacher training.

\section{INTRODUÇÃO}

O Programa Institucional de Bolsas de Iniciação a docência - PIBID, tem se mostrado como um divisor de águas para o desenvolvimento da docência seja, por sua organização, uma vez que, se diferencia dos Estágios Supervisionados de Formação, por trazer em sua proposta um caráter extracurricular, com uma carga horaria maior que a estabelecida pelo Conselho Nacional de Educação - CNE, seja, por proporcionar aos alunos bolsistas um tateamento experimental da docência, do ser professor, do estar em contato com a realidade em sala de aula e na escola e, ainda, por carregar concepções pedagógicas, filosóficas, sociológicas da docência, associadas e preocupadas com o lugar do professor nesse processo de mudança, de formação e, sobretudo, de aprendizagem, visto que, todos os atores sociais envolvidos, a saber: os coordenadores, os supervisores e bolsistas, buscam a partir de uma pluralidade de atividades e reflexões aproximar-se dos contextos sociais diversos e da realidade social escolar de modo a compreender as suas reais necessidades.

Antes de começarmos nossa reflexão, consideramos relevante contextualizar brevemente o lugar do artigo ora apresentado. Trata-se de um recorte da nossa dissertação ${ }^{3}$, realizada entre os anos de 2015 a 2017 no Programa de Pós Graduação em Educação na Universidade Federal do Rio Grande do Norte - UFRN, onde buscamos compreender como alguns estudantes participantes do PIBID/UFRN estavam construindo seus sentidos, suas representações de Docência a partir do contato com esse processo formativo inicial.

\footnotetext{
${ }^{3}$ A dissertação intitulada de "Representação Social e docência: um estudo sobre a formação de licenciandos da UFRN a partir do Programa Institucional de Bolsa de Iniciação a Docência (PIBID)" foi defendida no dia 22 de fevereiro de 2017 e está em processo de correção. Esta reflexão como já citado é um recorte do terceiro capítulo, onde tratamos especificamente o programa e a valorização da formação docente.
} 
Neste trabalho, traremos algumas pontuações em relação ao Programa e a sua relevância enquanto fomentador da valorização da formação docente. Para isso, buscamos nos orientar a partir de duas perspectivas, a saber: a importância de conhecer o Programa, desde seus objetivos, finalidades, partindo das suas portarias e o que essas desvelam na constituição de uma política pública de valorização da educação básica; e a segunda perspectiva é entender a relevância do PIBID como um articulador entre ensino, pesquisa e extensão, onde permite que os licenciandos que dele participam experimentem outros espaços formativos.

Diante dessas perspectivas, estruturamos nosso artigo da seguinte forma: primeiro, com os apontamentos iniciais, que nos permite conhecer um pouco o programa de modo geral - é importante ressaltarmos que o que trazemos é apenas uma perspectiva interpretativa para conhecer o programa, e esta aberta para que os demais estudiosos agreguem conhecimento à temática ora discutida -, seus objetivos, através da apresentação das suas legislações; segundo, o PIBID e o cenário atual, onde realizamos algumas breves considerações em relação aos possíveis desmontes que atingiram o programa; terceiro intitulamos de O PIBID/UFRN e a articulação entre ensino, pesquisa e extensão, onde buscamos refletir acerca das interações entre a universidade e a escola, assim como, com a comunidade escolar, possibilitando o que a Candau (2013) problematizou como interculturalidade ${ }^{4}$; O nosso quarto item foi para descrever os crescimentos e produções do PIBID/UFRN entre os anos de 2009 a 2014, no qual trazemos três dados que demostram essa crescimento, e as considerações finais, nas quais explicitamos algumas ponderações que concluímos com nossos estudos, pesquisas e reflexões, que não apresentamos de forma fechada e definitiva, nem muito menos como sendo verdades absolutas, mas apenas como uma perspectiva interpretativa para conhecer o PIBID.

\section{APONTAMENTOS INICIAIS: O PIBIB E SEUS OBJETIVOS}

O PIBID foi instituído através da Portaria Normativa ${ }^{\circ} 38$, de 12 de dezembro de $2007^{5}$, no âmbito do Ministério da Educação - MEC, da Coordenação de Aperfeiçoamento de Pessoal de Nível Superior - CAPES e do Fundo Nacional de Desenvolvimento da Educação - FNDE,

\footnotetext{
${ }^{4}$ Candau (2013) apresenta, que a reflexão em relação ao papel da Educação em uma sociedade com um caráter multicultural é recente e necessita ser entendida numa perspectiva intercultural, não separando a compreensão da educação da problemática social e politica de cada contexto.

5 A portaria pode ser visualizada no site da Capes:< https://www.capes.gov.br/images/stories/download/legislacao/Portaria_Normativa_38_PIBID.pdf>.
} 
com o intuito de fomentar a iniciação à docência dos estudantes das Instituições Federais de Educação Superior, buscando preparar esses discentes para a atuação na educação básica. $\mathrm{O}$ Ministério da Educação, por intermédio da Secretaria de Educação Superior - SESu, CAPES, e FNDE, ainda tornam público o referido programa, através do Edital 2007, que convocou os interessados a apresentar propostas de projetos institucionais, conforme as condições estabelecidas pelo Edital ${ }^{6}$. (BRASIL, 2007).

Inicialmente o Programa atendia as seguintes disciplinas e modalidades: para o Ensino Médio, com licenciatura em física, química, matemática e biologia; para o Ensino Médio e os anos finais do Ensino Fundamental, com ciências e matemática e de forma complementar com língua portuguesa, educação artística e musical e demais licenciatura. É notório que o PIBID foi pensado para atender aos cursos com baixa demanda, dada à carência de profissionais nessas áreas. Entretanto, com os primeiros resultados positivos e com o incentivo das políticas de valorização do magistério, em 2009 o programa passou a atender a toda a educação básica, incluindo Educação de Jovens e Adultos - EJA, de quilombolas, educação do campo e de indígenas. (DEB, 2013)

Entre as finalidades do PIBID postas na portaria que o instituiu está: incentivar a docência; valorizar do magistério; promover a articulada entre as universidades e a escola; além de elevar a qualidade da formação inicial e a promover a melhoria da qualidade da educação básica.

O programa foi implantado através de convênios específicos ${ }^{7}$ a serem compartilhados entre as instituições Federais de Educação Superior e a CAPES, proporcionando aos estudantes das licenciaturas o contato direto e imediato com a prática docente nas escolas, e essas foram selecionadas devido aos baixos Índices de Desenvolvimento da Educação Básica - IDEB e baixas médias no Exame Nacional do Ensino Médio - ENEM.

Dos critérios de seleção que estão contidos nessa primeira portaria estavam os resultados do Sistema Nacional de Avaliação da Educação Superior - SINAES, dos cursos a serem contemplados, as escolas em que os bolsistas atuariam, os acordos de cooperação instituídos com as redes de educação básica dos municípios, estados ou Distrito Federal, além das

\footnotetext{
6 Pode ser visualizado no site da Capes:< http://www.capes.gov.br/educacao-basica/capespibid/editais-eselecoes>.

${ }^{7}$ No paragrafo único do artigo segundo da portaria normativa ${ }^{\circ} 38$ de 12 de dezembro de 2007 , aparece que as Instituições federais de Educação Superior deverão promover convênios ou acordos com as redes de educação básica.
} 
estratégias de atuação dos bolsistas que consistiam em privilegiar ações articuladas e de modo planejado.

Ainda como critérios, deveriam ser selecionados, os alunos que fossem oriundos da rede pública e tivessem uma renda familiar de até um salário-mínimo e meio. Uma vez contemplado, tem que estar regularmente matriculado no curso de licenciatura, dedicar-se no período de validade da bolsa as atividades do PIBID sem prejuízo as atividades regulares dos seus cursos e assinar uma declaração expressando seu interesse em atuar na educação básica. Os professores supervisores deveriam ser essencialmente do quadro efetivo da rede pública, assim como os coordenadores das instituições federais. Para estes, seria necessário ainda, atuar enquanto docentes nos cursos de licenciatura e terem no mínimo três anos de experiência no magistério superior. (BRASIL, 2007).

Refletindo sobre os resultados positivos e sobre a amplitude do programa a CAPES publicou em 2009, uma nova portaria a de $\mathrm{n}^{\circ} 122$ de 16 de setembro, que repensou os objetivos, as finalidades e, sobretudo, o alcance do programa para os cursos de Licenciatura, levando em consideração o edital $n^{\circ}$ 02/2009 que foi publicado antes da portaria e que dispunha sobre a abrangência do PIBID para as Instituições Estaduais e a Portaria MEC n ${ }^{\circ} 1.243$ de 30 de Dezembro de 2009 que trouxe alguns reajustes das bolsas dos participantes.

A Portaria $\mathrm{n}^{\circ} 122$ de 2009 , trouxe em sua disposição a preocupação em garantir um programa com coerência e com engajamento para a iniciação a docência dos licenciando, onde os bolsistas deveriam se dedicar trinta horas mensais sem prejudicar seus respectivos cursos de licenciaturas, voltou-se ainda para a valorização do magistério, inserindo os licenciando no cotidiano escolar, para além desses objetivos, buscava proporcionar aos estudantes e futuros professores a participação em experiências metodológicas, tecnológicas e práticas da docência, levando em consideração o caráter inovador e interdisciplinar, buscando a superação de problemáticas identificadas no processo de ensino-aprendizagem, atentando para o desempenho das escolas em avaliações nacionais, como Provinha Brasil, Prova Brasil, Sistema de Avaliação da Educação Básica - SAEB, Exame nacional do ensino médio - ENEM, entre outras. (BRASIL, 2009)

Com esse documento o PIBID passou a atender a mais licenciaturas, auxiliando no processo de formação desses estudantes e incentivando a atuação na docência. Para o Ensino Médio, as licenciaturas contempladas foram: Física; Química; Filosofia; Sociologia; Matemática; Biologia; Letras-Português; Pedagogia; Licenciaturas que atendam a projetos interdisciplinares. Para o ensino fundamental: Pedagogia destacando prática de classe de 
alfabetização; Ciências; Matemática; Educação artística e musical; Licenciaturas que atendessem a projetos interdisciplinares. E de forma complementar: Letras - Língua estrangeira; Licenciaturas interculturais ${ }^{8}$; Licenciaturas voltadas apara educação no campo e para comunidades quilombolas; e demais licenciaturas desde que justificassem a sua relevância para o desenvolvimento da docência. (BRASIL, 2009)

Com essa extensão o Programa de Bolsas de Iniciação a Docência passou em 2010, por novas reflexões com a implementação de novas portarias e decretos para viabilizar a sua finalidade, que era e é a de apoiar a Iniciação a Docência, nesse sentido, no que tange a legislação, constituiu a portaria ${ }^{\circ} 72$ de 9 de abril de 2010, que estendeu o PIBID as instituições públicas municipais e comunitárias, confessionais e filantrópicas sem fins lucrativos, que ampliou a atuação no ensino fundamental para a modalidade EJA, de forma complementar voltou a se preocupar com a formação de professores para a educação infantil, seguido do Edital $n^{\circ} 18 / 2010$ que atendia as considerações da portaria $n^{\circ}$ 72. (BRASIL, 2010).

Já a portaria $\mathrm{n}^{\circ}$ 136, de 1 de julho de 2010, alterou a modalidade de aplicação de dotação orçamentária referente ao PIBID, o decreto $\mathrm{n}^{\circ} 7.219$ de 24 de julho de 2010 dispôs sobre o programa com colocações concatenadas com as portarias em relação aos seus objetivos, organização e sobretudo apoiando a iniciação a docência e que esta deveria ser realizada impreterivelmente em escolas da rede pública, visando a valorização do magistério e da qualidade da educação básica. O edital conjunto de 22 de outubro de 2010 CAPES/SECAD ${ }^{9}$ Secretaria de Educação Continuada, Alfabetização e Diversidade -, que dispôs sobre o PIBID diversidade, e lançou o programa para alunos de licenciatura do SECAD, sendo o Programa de Apoio à Formação Superior e Licenciaturas Interculturais Indígenas- PROLIND e o Programa de Apoio à Formação Superior em Licenciaturas em Educação no Campo - PROCAMPO e a portaria $n^{\circ} 206$ publicada em 30 de Dezembro de 2010 que aprovou as normas gerais do programa, apontando as características necessárias das propostas quanto aos requisitos, objetivos, proponentes, projetos institucionais, assim como as propostas. (DEB, v.1, 20092014, p. 67-68, grifo nosso).

\footnotetext{
${ }^{8}$ Voltadas para a formação de professores indígenas.

${ }^{9}$ Este edital buscou contemplar subprojetos distintos em âmbito do Prolind e Procampo, e atendeu as seguintes áreas de licenciatura: Línguas/Linguagens e códigos; Ciências da Natureza e matemática; Ciências Humanas e Sociais; Ciências Agrárias/ Desenvolvimento Agroecológico, podendo esta área ser transversais as demais, dependendo da proposta de cada instituição; e outros desenhos curriculares a serem avaliadas pela comissão avaliadora.
} 
Diante de todas as menções positivas que o programa vinha trilhando na sua trajetória desde sua implantação, em 2011 a Coordenação de Aperfeiçoamento de Pessoal de Nível Superior - CAPES, tornou público que receberia das instituições públicas de Ensino Superior propostas contendo projetos de iniciação à docência, a serem apoiados no âmbito do Programa Institucional de Bolsa de Iniciação à Docência - PIBID, atendendo às atribuições legais da CAPES de induzir e fomentar a formação inicial e continuada de profissionais do magistério. Em 2012 para atender as demandas e novas propostas é lançado outro edital que permite ampliação do programa para as Instituições de Ensino Superior - IES, que já tivessem projetos e para as IES novas que possuíssem cursos de licenciatura e um projeto institucional que corroborasse com a proposta do PIBID.

Nesta perspectiva a portaria ${ }^{\circ} 096$, de 18 de julho de 2013 é publicada com a finalidade de aperfeiçoar e atualizar as normas do Programa Institucional de Bolsa de Iniciação a Docência, revogando a portaria ${ }^{\circ} 206 / 2010$. Esta nova portaria lançou um novo olhar para o fomento da iniciação a docência, contribuindo para o aperfeiçoamento da formação de docentes em nível superior e para a melhoria da qualidade da educação básica pública brasileira.

Esta portaria estava organizada da seguinte forma, o capítulo I das disposições gerais: da seção I das definições; seção II dos objetivos que não se mostraram tão discrepantes em relação à portaria anterior, havendo apenas o acréscimo de que o PIBID deveria também “contribuir para que os estudantes de licenciatura se insiram na cultura escolar do magistério, por meio da apropriação e da reflexão sobre instrumentos, saberes e peculiaridades do trabalho docente" (BRASIL, 2013). No Capítulo II observou-se as características do projeto e dos subprojetos, colocando que o PIBID deveria assumir diversas dimensões da iniciação a docência, desde o estudo contextual, planejamentos, a elaborações ativas no espaço escolar; Na Seção II tinham colocações da seleção dos projetos indicando o que deveria conter além dos critérios; Já no Capítulo III, compreendia os requisitos para a participação das Instituições de Ensino Superior; O Capítulo IV incluía as atribuições das instituições envolvidas. (BRASIL, 2013).

Ainda em relação à portaria 096 destacamos o Capítulo V que apresentava as perspectivas financeiras, na seção I, trazendo os tipos de apoio concedidos, da seção II, dos recursos de custeio, Seção III dos recursos de capital; No Capítulo VI que compreendia das bolsas, a seção I apresentava pontuações referentes às modalidades e o tempo de duração das bolsas, seção II do quadro de bolsas, seção III dos requisitos das bolsas, seção IV das vedações, seção V dos deveres dos bolsistas, ou seja, dos coordenadores, supervisores e alunos da licenciatura, seção VI do cadastro de pagamento de bolsas, seção VII da suspenção, seção VIII do cancelamento, 
seção IX da devolução da bolsa; Já no Capítulo VII cuja denominação é da implementação do projeto, a sua seção I traz a contratação da proposta e forma de repasse, a seção II da seleção do bolsista, seção III do marco inicial do projeto, seção IV do regulamento interno; No Capítulo VIII da comissão de acompanhamento do PIBID o que dá maior visibilidade ao programa, uma vez que, observa-se os resultados obtidos e que esses estão sendo acompanhados; O Capítulo IX do acompanhamento e da avaliação com relatórios, mostram como o PIBID tem sido decisivo no processo de formação dos estudantes e para as escolas; O Capítulo X das prestações de conta e por fim, o Capítulo XI das disposições finais.

Após essa nova portaria, o programa divulgou dois editais, sendo estes respectivamente, os de $n^{\circ} 061$ e 066 de 2013, cujo primeiro tornou público que receberia das IES propostas e projetos a serem apoiadas no âmbito do PIBID e atendendo as concessões legais de fomentar a iniciação a docência, seguindo ainda as diretrizes do Plano Nacional de Metas Compromisso Todos pela Educação e o edital n ${ }^{\circ} 066$ tornou público que receberia de IES públicas e privadas sem fins lucrativos, propostas de projetos de Iniciação a docência no âmbito do PIBID diversidade, atendendo a Lei de Diretrizes e Bases da Educação Nacional, buscando o fomento da formação dos licenciando.

Durante a reflexão realizada percebemos a relevância do PIBID na formação inicial dos licenciando nas Universidades, sendo este, um momento impar na vida desses estudantes, integrando-se a docência desde os primeiros momentos de curso, entretanto, nos anos recorrentes até o momento em que este trabalho foi sendo tecido, o programa passou por dúvidas, especulações, não no que diz respeito a sua importância, tampouco pela sua expressividade, mas em relação aos desmontes na política Nacional que não o afetou somente, mas outras instâncias da educação e de outros setores da sociedade que foram atingidos de algum modo, durante o percurso vivenciamos momentos de transições e liquidez na política e este fator pôs em evidência todos os elementos que estavam e estão ligados aos parâmetros da política Nacional de Educação.

O programa passou por novas configurações com a publicação da Portaria n ${ }^{\circ} 46$ de 11 de abril de 2016 que foi revogada pela $n^{\circ} 84 / 2016$ sendo esta alterada pela $n^{\circ} 120 / 2016$, indicando em seu artigo 1 a revogação da Portaria ${ }^{\circ} 46$ de 11 de Abril de 2016, publicada no DOU de 15 de Abril de 2016, seção 1, pág. 16, que aprovou o Regulamento do Programa Institucional de Bolsa de Iniciação a Docência - PIBID, e em seu paragrafo único, colocou que os projetos em andamento continuariam regidos pela portaria $n^{\circ} 096$ de 18 de Julho de 2013, publicada no DOU, de 23 de julho de 2013, seção 1 pág. 11/14. O que assinalou que muitas oscilações em 
relação à manutenção ou continuidade do Programa, mas também sinalizou perspectivas de reações contra as restrições com as quais o programa vinha passando.

Essa portaria levou a um intenso momento de mobilizações entre os coordenadores, supervisores e estudantes que passaram a buscar a institucionalização do PIBID, para que não continuassem a serem alvo de possíveis cortes, o que afetaria de forma expressiva a formação dos futuros licenciando e também como dimensão de formação continuada para os professores das escolas que passaram a interagir com novos saberes na relação com os estudantes e com as instituições formadoras.

\section{O PIBID E O CENÁRIO ATUAL: BREVES CONSIDERAÇÕES}

Desde o final de 2014, os sujeitos ligados ao PIBID (coordenadores, supervisores, estudantes) passaram a observar momentos de sutilezas no programa, entretanto, as atividades continuaram a seguir. Durante o V Encontro Nacional das Licenciaturas (ENALIC) e IV Seminário Nacional do PIBID entre os 8 a 12 de Dezembro de 2014 realizado em Natal/RN, foi encaminhada a Carta de Nata ${ }^{10}$ aprovada em Assembleia e lida publicamente na sessão de encerramento do evento, que continha a relevância do programa enquanto politica pública de formação a docência ao MEC e CAPES e demais instituições, assinalando a disposição do Forpibid $^{11}$ dos coordenadores Regionais eleitos em Assembleia, em continuar com o diálogo e com a interlocução entre as Instituições de Ensino Superior, assim como, em deixar objetivado a representatividade do interesses do PIBID e do PIBID diversidade, buscando a melhoria e a valorização da docência e da educação básica pública.

A carta que argumentava acerca da relevância do programa trazia que naquele contexto 90.254 bolsistas de Iniciação a Docência, de Supervisão e de Coordenação, em 284 Instituições de Educação Superior, com 313 projetos em 5.898 escolas de Educação Básica, no campo, em terras indígenas, nos quilombos, nas pequenas e grandes cidades, e que demonstrava o fortalecimento e o dialogo intenso entre as IES e a escola o que é de extrema importância, uma vez que, pode-se observar concretamente a realidade escolar e não mais ficar no plano da teoria.

\footnotetext{
10 Este documento pode encontrado no site: <http://pibid.cpdoc.fgv.br/sites/pibid.cpdoc.fgv.br/files/u27/oficio_forpibid_01-2014_carta_de_natal.pdf>.

${ }^{11}$ É o Fórum Nacional de Coordenadores Institucionais do Programa Institucional de Bolsas de Iniciação a Docência, foi aprovado em Uberaba - MG em 2013 onde buscaram criar uma entidade representativa de caráter permanente para atuarem como interlocutores entre os programas e a Capes.
} 
O PIBID trouxe a inserção na prática, o saber docente incentivado pela experiência, possibilitou ao aluno da licenciatura um tateamento da docência, que articulada com a teoria aprendida nas IES, através dos fundamentos pedagógicos, sociológicos, filosóficos, antropológicos, psicológicos, passando a subsidiar essa experimentação a cerca da docência.

Esse documento refletido durante o ENALIC/2014 trouxe treze argumentos que demonstravam a legitimidade e relevância do programa. Esses argumentos foram pensados em uma atividade reflexiva, coletiva e paulatinamente. O PIBID tem efetuado as seguintes indicações para o fomento da docência segundo a Carta analisada: A revitalização das Licenciaturas; A permanência dos licenciando nos cursos; A vivência dos licenciando com as comunidades escolares sob a supervisão de professores que integram o Programa; O reconhecimento do professor da Educação Básica como conformador; O compartilhamento de práticas formativas entre as diversas áreas de conhecimento; A melhoria da qualidade do ensino com práticas docentes diversificadas; A interlocução das IES com as escolas e com a comunidade; A melhoria do desempenho dos estudantes da Educação Básica e a motivação para seguirem seus estudos; A ampliação dos espaços de discussão sobre as práticas docentes e sobre as Licenciaturas nas IES; O desenvolvimento de práticas educativas afirmativas pautadas na diversidade cultural; A sinergia entre os demais programas da CAPES, a exemplo do PARFOR, LIFE, PRODOCÊNCIA, NOVOS TALENTOS. A apropriação criativa das tecnologias da informação e comunicação; $O$ desenvolvimento de projetos e práticas interdisciplinares. (OFÍCIO CIRCULAR FORPIBID, 2014).

Essas indicações demonstra a relevância do programa, em relação à valorização da docência, em buscar a elevação da qualidade da Educação Básica, assim como, um importante meio de dialogo e de cooperação conjunta, como um instrumento concreto de formação inicial e para além dessas indicações, percebeu a relevância do PIBID como dimensão de formação continuada para os professores das escolas públicas, podendo nessa relação dialógica aprender novo saberes, metodologias, e estar aberto a proposições da sociedade atual, em constante transformação. É ainda possível através dessa relação, perceber representações e sentidos de docência diversos, com olhares subjetivados, mas que condizem com o contexto e com a realidade social, cultural e política do momento.

Apesar de todas essas justificativas e argumentos assinalando a relevância do Pibid, no ano de 2015 as incertezas e dúvidas passam a tomar maiores proporções, assim como, os embates travados pela sua defesa. Em 15 de dezembro de 2015 a Capes emitiu a circular de $\mathrm{n}^{\circ} 018 / 2015$ que identificava a fragilidades de articulação, e que o Pibid foi dentre os programas 
o que teve maior expansão, tendo em 2013 quarenta mil bolsas e em 2014 noventa mil. Assim, sem orçamento suficiente, seriam obrigados a remanejar recursos para honrar as bolsas dos estudantes. Os alunos que completassem vinte e quatro meses de bolsa, não poderiam continuar no programa nem serem substituídos. Outra circular, a de $\mathrm{n}^{\circ}$ 02/2016 de 18 de fevereiro de 2016, informou que a Capes não prorrogaria as bolsas, o que gerou movimentos contra essas medidas ganhando expressividade no dia 24 de fevereiro de 2016 como o Dia Nacional de Mobilização do PIBID.

Diante da situação, o Forpibid se fez presente para tentar meios de superar tais conflitos e esses representantes do Pibid conseguiram uma reunião com o então Ministro da Educação Aloísio Mercadante e durante o encontro o Ministro iniciou explicando a proposta de novo edital do PIBID, enfatizando a meta do PNE de colocar todas as crianças de 4 e 5 anos na escola e alfabetizá-las no máximo até 8 anos de idade, argumentou ainda da necessidade de uma formação de professores em nível superior mais comprometida com os problemas da escola, e do protagonismo das redes de ensino e, finalizou, afirmando que o PIBID é um programa estratégico por ser o principal instrumento de articulação da formação de professores com a prática docente, deixando evidente que estavam buscando realizar mudanças no Pibid, a fim de redesenhar a proposta do programa, mas também de outros, a saber, o Programa Nacional de Alfabetização na Idade Certa - PNAIC e o Programa Mais Educação - PME . Apesar dos argumentos usados pelo Ministro, o Fórum dos Coordenadores Institucionais do PIBID FORPIBID manteve o pedido a Capes para que cumprissem o compromisso acordado com as IES e mantivessem os projetos institucionais do Pibid e Pibid diversidade, consentido pelo edital 061/2013 e 066/2013, regidos pela portaria 096/2013.

Em 11 de abril de 2016, foi lançada uma nova portaria, a de $n^{\circ} 46$ que trouxe justamente as propostas de mudanças sinalizadas anteriormente, gerando muitas críticas devido as suas orientações verticalizadas. A portaria aprovou o Regulamento do Programa Institucional de Bolsas de Iniciação a Docência, revogando a portaria 096/2013, acentuando as angustias de seus participantes em relação ao futuro do programa.

Dentre as propostas de mudanças sinalizadas pela portaria $n^{\circ} 46$ de 2016 estava à articulação entre o PIBID e outros programas como o Programa Nacional de Alfabetização na Idade Certa - PNAIC, Programa Mais Educação - PME, Programa Ensino Médio Inovador PROEMI e Pacto pelo Fortalecimento do Ensino Médio - PNEM, dando o indicativo de que o programa não seria desenvolvido por si só, mas em conjunto, além de que, nem todas as licenciaturas teriam visibilidade e se limitariam aos cursos de Pedagogia, Letras, Ciências, 
Matemática, Biologia, Física, Química, Geografia, História, Filosofia e Sociologia, deslegitimando as outras disciplinas, que por mais que pensassem na possibilidade de serem trabalhadas de forma interdisciplinar, perdiam sua voz e suas autonomias.

Essa imposição demostrou de certo modo um caráter hierárquico e de importância dada a algumas disciplinas, levando a um processo de desvalorização, por mais que esse não tenha sido o real motivo da portaria, nem muito menos a intenção, o que ficou subliminar é que existem disciplinas que possuem um grau de importância maior que outras, o que não concordamos. Nesse sentido, Morin (2004) chamou para se pensar a compartimentalização do saber e que foi duramente criticado pelo mesmo, trazendo uma discussão extremamente importante de que a inteligência parcelada, compartimentada, rompe com o complexo, quer dizer com os elementos que são inseparáveis, que fazem parte de um mesmo conjunto de saberes que podem ser explicados por si mesmos, mas que possuem inter-relações, quando não há essa dialógica, esse mecanismo de união não se consegue alcançar uma conhecimento geral que compreende o contexto, o político, o econômico, o social, o cultural, o afetivo da sociedade, ou seja, impede aprender "o que está tecido junto" (MORIN, 2004, p. 45).

A portaria implementada em 2016 foi realizada sem dialogo, com imposições verticalizadas e com muitas restrições, que não nos cabe realizar uma análise aprofundada, o que tentamos com essa reflexão é chamar atenção para aquilo que mais ficou evidenciado em relação ao próprio desenvolvimento do programa, em pensar não nos rumos, mas, sobretudo o que trouxe de positivo ou não para os licenciandos participantes, que são os sujeitos ativos do processo, e que nós consideramos como os principais atores sociais desse projeto de Iniciação a Docência, sem os alunos, sem suas motivações para o exercício da docência não teria sentido.

\section{O PIBID/UFRN E A ARTICULAÇÃO ENTRE ENSINO, PESQUISA E EXTENSÃO}

O PIBID da Universidade Federal do Rio Grande do Norte possui uma proposta institucional relevante e tem nutrido junto aos estudantes da licenciatura o interesse e a motivação para a atividade docente. Ramalho e Nuñez (2011) ao estudar as necessidades formativas, partindo da teoria da atividade em Leontiev, refletem que a formação docente enquanto um tipo de atividade, "orienta-se por motivos, por fins a serem alcançados". (RAMALHO E NUÑEZ 2011, p. 74).

Partindo dessa perspectiva o PIBID tem desempenhado esse papel de possibilitar aos estudantes em formação, motivações para o desenvolvimento da atividade docente, não apenas 
refletindo acerca de problemáticas em relação ao ensinar, a escola, mas tem oportunizado a aprendizagem de arranjos didáticos e novos ecossistemas educativos (CANDAU, 2013) que atendam as diversas realidades sociais, permitindo aos estudantes um conhecimento plural e contextualizado, nesse sentido, na perspectiva do Boaventura Santos (2005).

[...] o conhecimento pluviversitário é um conhecimento contextualizado na medida em que o princípio organizador da sua produção é a aplicação que lhe pode ser dada. Como essa aplicação, acontece extra-muros, a iniciativa da formulação dos problemas que se pretende resolver e a determinação dos critérios da relevância destes é o resultado de uma partilha entre pesquisadores e utilizadores. (SANTOS, 2005, p. 41).

O programa tem oportunizado aos estudantes participantes perceber a dissociação entre ensino, pesquisa e extensão na prática, permitindo-os a inserção nas escolas, conhecendo os diversos contextos educativos, as problemáticas nas quais se inserem para que possam refletir em soluções ativas, o PIBID de modo geral tem essa características de tateamento da prática e de possibilitar uma formação plural em espaços formativos para além da Universidade, sendo essa formação acontecida extra-muros como coloca o autor.

Com isso, consideramos de grande pertinência apresentar mesmo que brevemente o lugar que o PIBID/UFRN ocupa nessa reflexão. Partiremos, portanto, de algumas pontuações acerca dos seus projetos institucionais e do regimento interno Institucional, de modo que possamos conhecer um pouco da historia do PIBID/UFRN e de como está estruturado e sistematizado.

O primeiro projeto institucional da UFRN foi realizando em consonância com o Edital n 02/2009 e coordenado pelo professor Paulo Cezar de Faria, primeiro coordenador institucional do PIBID/UFRN, sinalizando em seu plano de trabalho a relevância de um enforque interdisciplinar que pudesse possibilitar a superação de um ensino fragmentado; $\mathrm{O}$ segundo projeto institucional, organizado a partir do Edital $n^{\circ} 001 / 2011$, foi realizado pelo professor André Ferrer Pinto Martins, trouxe uma reflexão acerca da recente aprovação do Plano Nacional de Educação para o decênio 2011-2020, buscando a universalização do ensino, superação das desigualdades educacionais, além de incentivar a valorização da docência, para que fosse alcançada uma educação de melhor qualidade. O terceiro projeto relacionado ao Edital $n^{\circ}$ 61/2013 que inclusive rege atualmente o PIBID/UFRN, que foi elaborado pelo professor Lucrécio Araújo de Sá Junior, que partiu da perspectiva de conhecer o local, o contexto do Rio Grande do Norte e dessa forma problematizar o lugar da UFRN nessa atuação e interlocução com a educação do estado. Todos os documentos se mostraram analisado se respaldaram na Lei de Diretrizes e Bases da Educação Nacional (Lei n 9.394 de 1996), além de trazem pertinentes contribuições para se pensar nas possibilidades de alcançar uma educação 
de qualidade, através da formação inicial dos licenciando e da valorização do professor enquanto sujeito ativo e reflexivo.

Buscando compreender as proposições técnicas, nos debruçamos no regulamento Interno do Programa Institucional de Bolsa de Iniciação a Docência/PIBID-UFRN que normatizou o funcionamento do programa na UFRN. Foi aprovado em 12 de março de 2013 sob a Resolução $\mathrm{n}^{\circ}$ 033/2013- CONSEPE $^{12}$ e normatizou o funcionamento do programa em consonância com a Portaria $n^{\circ} 260 / 2010$, contendo em seu parágrafo único, que esse regulamento estaria passível de mudança, de acordo com as portarias que surgissem posteriormente.

Do ponto de vista estrutural o documento possui 44 artigos divididos em: Disposições Gerais; Dos objetivos; Das caraterísticas do programa; Da vinculação institucional; Da composição da equipe do PIBID - UFRN; Da gestão acadêmica e de recursos; Das áreas contempladas pelo PIBID; Da seleção de Bolsistas do PIBID- UFRN; Da substituição dos bolsistas do PIBID-UFRN, Das disposições Gerais.

Entre o que consideramos dentro da nossa análise e sabendo que todo o documento foi realizado com coerência e reafirmando a importância do programa, o seu artigo 2, que dispõe sobre seus objetivos chamou nossa atenção por trazer a importância de: incentivar a participação dos estudantes em atividades e experiências didáticas - pedagógicas que estivessem concatenadas com as políticas educacionais (Lei de Diretrizes e Bases da Educação - 9.394/1996; Parâmetros Curriculares Nacionais e Diretrizes Curriculares Nacionais), dando a escola um lugar de visibilidade nesse processo de formação; desencadear uma formação continuada aos professores das escolas públicas vinculadas ao PIBID, proporcionado aos mesmos um incentivo e uma coparticipação na produção de conhecimentos mostrando-os como protagonistas desse processo; promover os intercâmbios de saberes entre os alunos e as realidades escolares, de modo que permitisse um entendimento da realidade social a qual estavam inseridos.

Ao pensar nessa reflexão é pertinente nos reportamos ao Nóvoa (2009), quando reflete a importância do professor ter o seu processo formativo realizado dentro da profissão, ou seja, baseada na aquisição de uma cultura profissional ancorada numa práxis reflexiva ${ }^{13}$, onde constituirá saberes que o leve, a conscientização e a transformação social e educativa.

\footnotetext{
${ }^{12}$ Colegiado Superior de Ensino, Pesquisa e Extensão.

${ }^{13}$ Ao pensar na Práxis reflexiva, estamos nos reportando às perspectivas marxistas de que o sujeito transforma e é transformado num processo dialético, para isso, nos respaldamos em Marx e Engels (1998) que partem da ideia de que as atividades práticas transformadoras do mundo estão dentro do processo produtivo, Vázquez (1977) que
} 
Continuando nossa análise do regulamento interno, no artigo 5 também aparece a interação entre os sujeitos e o trânsito entre os saberes como algo que deve ser pensando em todos os processos de formação; e da possibilidade de quando necessário haver um contato mais concreto com a comunidade escolar o que chamou de em "situações especiais", os demais artigos são descrevendo as características organizacionais do programa institucional que esta associado aos critérios também organizacionais das portarias do PIBID.

Com essa breve reflexão acerca do que nos chamou atenção no regulamento institucional é possível perceber o esforço do PIBID/UFRN em manter acesa, as possibilidades de interações entre a academia e a escola, assim como, a comunidade escolar, possibilitando uma interação entre os saberes e principalmente, não mantendo para si um conhecimento que precisa ser compartilhado, para que possa ser construída uma educação onde todos possam ter acesso, seguindo dessa forma à busca pela qualidade da Educação Pública.

\section{O PIBID/UFRN: CRESCIMENTOS E PRODUÇÕES (2009 A 2014)}

No ano de 2009 o PIBID/UFRN dispunha de oito subprojetos os quais comtemplavam as seguintes disciplinas: Biologia; Física Letras Português (Natal); Letras Português (Currais Novos); Matemática (Natal); Matemática (Caicó); Música; Química. No ano de 2010 além desses subprojetos acrescentaram: Ciências Sociais; Filosofia; Geografia (Natal); História (Natal); História (Caicó); Pedagogia (Natal), somando para quatorze o número de subprojetos.

Em 2011 houve um importante crescimento em relação aos subprojetos que estavam organizados da seguinte forma: Ciências Sociais, Filosofia, Geografia (Natal), História (Natal), História (Caicó), e Matemática (Caicó) continuaram com um subprojeto e os cursos de biologia, física, Letras Português (Natal), Letras Português (Currais Novos), Matemática (Natal), Música e Química passaram a constituir dois subprojetos e Pedagogia (Natal) com três subprojetos, evidenciando a prosperidade do programa.

Em 2012 houve nova expansão e os subprojetos passaram a organizar-se da seguinte forma: Ciências Sociais, Filosofia, Geografia (Natal), História (Caicó) e História (Natal) continuando cada com um subprojeto. Biologia, Física, Letras Português (Natal), Letras Português (Currais Novos), Matemática (Caicó), Matemática (Natal), Música e Química

entende a práxis como atividade da consciência humana e Paulo Freire (1996) que traz a reflexão da ação- reflexãoação. 
estavam com dois subprojetos. Pedagogia com três subprojetos e acrescentaram um subprojeto para pedagogia (Caicó) e dois subprojetos para os cursos de Educação Física, Geografia (Caicó) e letras Inglês.

Se em 2012 observamos o crescimento do programa, nos anos seguintes não foi diferente, 2013 e 2014 tiveram avanços em relação ao aumento dos subprojetos e consequentemente de suas produções e atuações, mas principalmente no estreitamento entre a Universidade e a escola pública. Em 2013 tinham os seguintes subprojetos divididos em: um, pedagogia (Caicó), dois Biologia, Ciências Sociais, Educação Física, Filosofia, Geografia (Caicó), Geografia (Natal), História (Caicó), História (Natal), Letras Inglês, Letras Português (Natal), Letras Português (Currais Novos), Matemática (Caicó), Música, Química e Teatro. Com três subprojetos tinham Matemática (Natal), Pedagogia (Natal) e com quatro subprojetos Física.

E, por fim, 2014 somaram-se vinte e sete subprojetos do Pibid nas diversas áreas de conhecimento: Biologia; Biologia EAD (Natal e Nova Cruz); Ciências Sociais Dança Educação Física, Filosofia, Física, Física EAD (Natal e Nova Cruz); Geografia (Caicó); Geografia (Natal); Geografia (Nova cruz); Historia (Natal); Historia (Caicó); Letras espanholas; Letras inglês; Letras Português; Letras Português (Currais Novos); Letras Português EAD (Currais Novos); Matemática (Caicó); Matemática (Natal); Música; Pedagogia (Natal) Pedagogia (Caicó) Pedagogia EAD; Química; Química EAD (Natal) e Teatro.

No quadro abaixo esta esse crescimento em gráfico, onde podemos visualizar de forma didática como o PIBID/UFRN tem se expandido, inclusive para os campus no interior do Estado do Rio Grande do Norte.

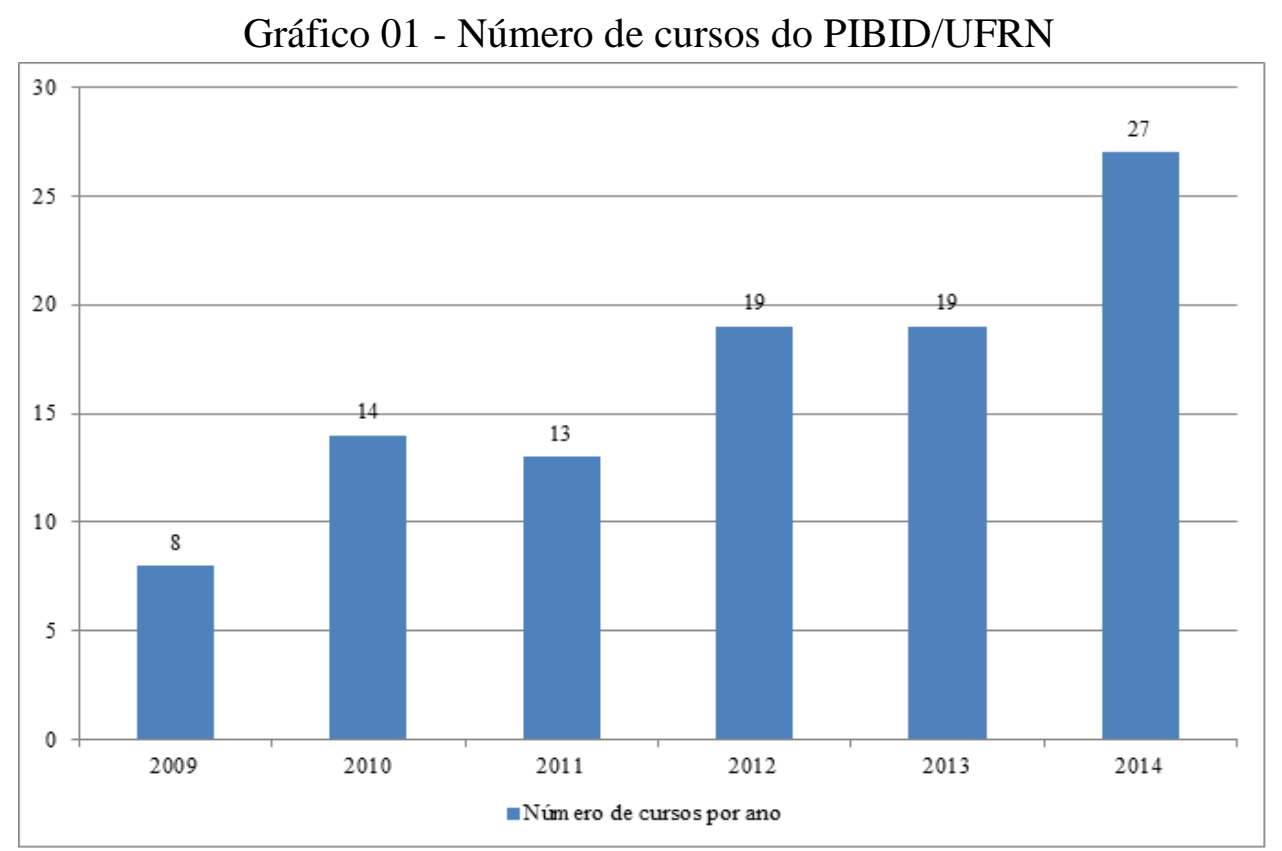

Momento: diálogos em educação, E-ISSN 2316-3100, v. 27, n. 2, p. 264-284, mai./ago, 2018. 
Fonte: Coordenação Institucional PIBID/UFRN, 2016.

Os dados expostos no Gráfico 01 corroboram com as nossas reflexões em relação à relevância do programa na valorização docente, mostrando o crescimento no número de cursos por ano entre 2009 a 2014, onde tivemos em 2009, o surgimento de oito cursos, na qual passou gradativamente por um relevante crescimento, em 2010 passou para quatorze, em 2012 e 2013 passou a serem dezenove cursos e 2014 avançou para vinte e sete cursos, nos dando o entendimento de que o programa tem se efetivado e que tem fomentado a formação docente.

A Tabela 01 mostra a quantidade de participantes $^{14}$ que passaram por esse processo formativo entre os anos de 2009 a 2014.

Tabela 1 - Total de participantes do PIBID/UFRN - 2009 a 2014

\begin{tabular}{cccccc}
\hline Ano & Bolsistas & Supervisores & Coordenadores & Coord. Inst. & $\begin{array}{c}\text { Coord. } \\
\text { Gestão }\end{array}$ \\
\hline $\mathbf{2 0 0 9}$ & 80 & 8 & 8 & 1 & 1 \\
$\mathbf{2 0 1 0}$ & 284 & 30 & 22 & 1 & 1 \\
$\mathbf{2 0 1 1}$ & 237 & 30 & 14 & 1 & 1 \\
$\mathbf{2 0 1 2}$ & 420 & 46 & 23 & 1 & 1 \\
$\mathbf{2 0 1 3}$ & 420 & 46 & 23 & 1 & 1 \\
$\mathbf{2 0 1 4}$ & 809 & 107 & 47 & 1 & 4 \\
\hline
\end{tabular}

Fonte: Coordenação Institucional PIBID/UFRN, 2016.

Percebemos que muitos participantes foram contemplados com a participação no PIBID e que houve um crescimento significativo nos anos seguintes. Em 2009 havia oitenta alunos e em 2014 aumentou-se esse número para 809, os supervisores em 2009 eram 8, já em 2014 passou para 107, um aumento relevante, visto que, o nosso olhar em relação ao programa, isto é, entendemos o PIBID como um programa que viabiliza a formação inicial e a continuada de modo conjunto. Teve-se aumento nos coordenadores, em 2009 tínhamos oito e passou para quarenta e sete em 2014. Dos coordenadores institucionais continuamos com a mesma quantidade e o de Gestão teve um pequeno aumento em 2009 tínhamos um coordenador e em 2014 passou para quatro.

Esses são sem duvida, crescimentos significativos para o PIBID/UFRN, e, sobretudo para os participantes, uma vez que, estão intrinsicamente ligados ao processo formativo e em

\footnotetext{
${ }^{14}$ Refere-se a todos os envolvidos no Programa PIBID/UFRN (2009-2014).
} 
contato com a realidade social e escolar. Entretanto, é pertinente, colocarmos que ainda alcança um número mínimo se for pensar em nível de Universidade, no que se refere ao desenvolvimento formativo, visto que, entendemos que o PIBID e suas especificidades devem perpassar e ser referencia para os que não têm a oportunidade de fazer parte, sem que haja dessa forma uma formação dual, mas que proponha com seu modelo formativo, atingir ao máximo os futuros profissionais docentes sejam eles pertencentes ou não ao programa.

O Gráfico 02 nos traz o crescimento dos subprojetos por curso, onde podemos verificar o aumento desses subprojetos entre os anos de 2009 a 2014.

Gráfico 02 - Crescimento de cursos com subprojetos PIBID/UFRN (Natal)

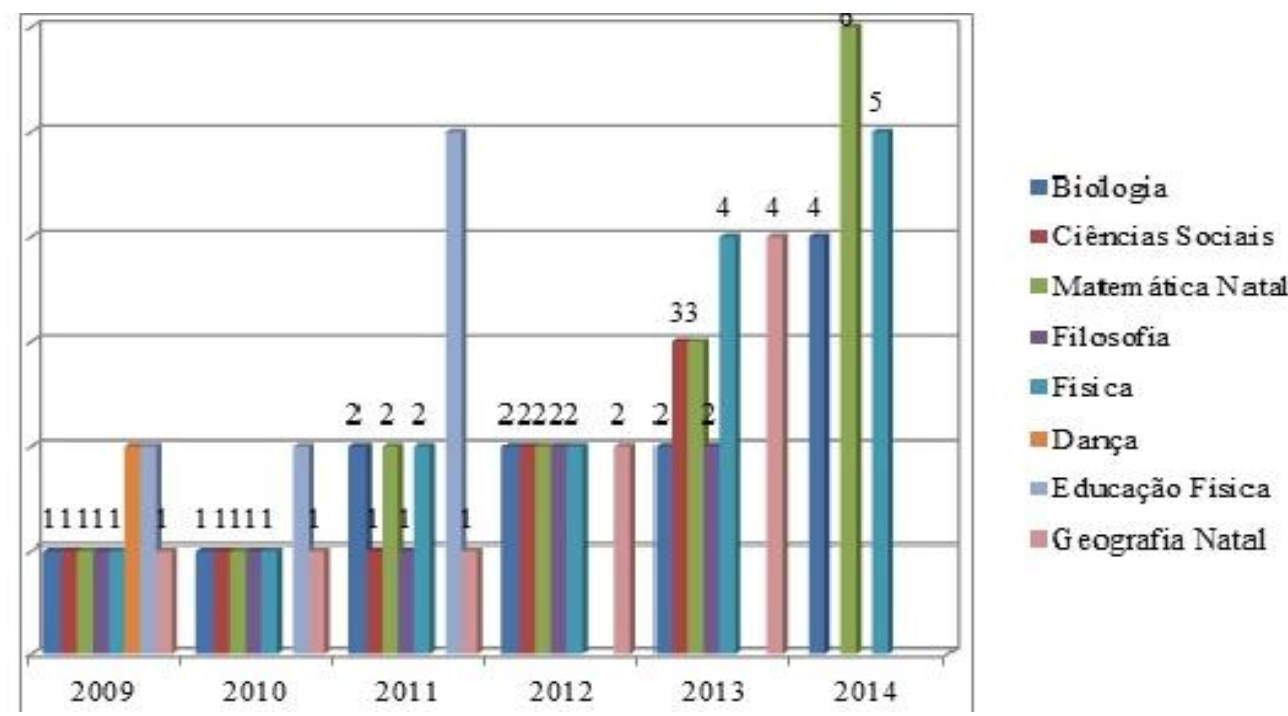

Fonte: Coordenação Institucional PIBID/UFRN, 2016.

É perceptível que durante os anos supracitados tivemos um crescimento nos subprojetos, contemplando diversos cursos, fomentando as diversas áreas de conhecimento, oportunizando aos estudantes da licenciatura uma prática mais efetiva com a docência através do Pibid.

Esses dados corroboram com o exercício de reflexividade proposto neste artigo de pensar a relevância do PIBID e, sobretudo do PIBID/UFRN para a formação e valorização docente, visto que, insere os estudantes na prática de modo ativo, onde esses passam a conhecer melhor as realidades singulares da educação da sua região, e passam a ampliar seu campo de visão para as estratégias que devem ser efetivadas para buscar uma educação de qualidade, relacionadas à formação do sujeito crítico e reflexivo.

\section{CONSIDERAÇÕES FINAIS}


Neste trabalho buscamos elucidar algumas considerações em relação a nossa pesquisa de mestrado, no qual tivemos uma diversidade de possibilidades interpretativas para pensar o lugar do PIBID no processo formativo inicial dos licenciandos da UFRN.

Desse modo tentamos pontuar o PIBID enquanto politica publica de relevância que têm permitido aos estudantes das licenciaturas uma tateamento experimental com a prática docente e como um instrumento de valorização da docência, permitindo aos bolsistas uma formação ampla e plural em diversos espaços formativos para além da Universidade, rompendo com a ideia de que conhecimento só se produz na academia.

O PIBID na sua singularidade tem permitido uma intercomunicabilidade entre espaços de aprendizagens diversos, seja na própria universidade, nas escolas, na comunidade escolar, e também em ampliar as perspectivas de constituição dos saberes, que são realizados efetivamente dentro desses espaços citados anteriormente e nas estratégias de ensino, seja na pesquisa, no estudo, nos encontros realizados, nas relações interpessoais que são evidentemente um somador nesse processo de formação desses estudantes.

Durante o percurso de reflexão apresentado neste trabalho, desvelamos o PIBID enquanto programa de política pública com a apresentação e interpretação de suas portarias que demostram sistematicamente seus objetivos, seus critérios, e suas perspectivas de ação, trazendo que dentro das finalidades é buscar o fomento da formação docente e da valorização da profissão, além de apontar de forma subliminar a relevância de esses estudantes terem entendimentos dos seus conhecimentos específicos, mas também pedagógicos, sociológicos, filosóficos e da prática, das experiências.

Deste modo, reiteramos o PIBID enquanto divisor de águas para o processo formativo e para o desenvolvimento da docência, porque tem buscado refletir acerca dos saberes constituintes da docência, tem oportunizado aos licenciando um tateamento com a prática profissional, tem permitido a intercomunicabilidade entre Universidade e Escola e incentivado as relações interpessoais entre seus participantes, que estão em movimento, constituindo novos saberes, novas práticas, novos materiais e estratégias de ensino, partindo sempre das suas realidades sociais, locais e regionais, o PIBID é sem dúvida uma Política Pública de formação de relevância, mas que precisa ser continuamente repensada para que possa ampliar suas proporções na formação, garantindo, dessa forma, uma formação docente significativa e coerente com o que se busca: a democratização e qualidade do ensino e da escola pública. 


\section{REFERÊNCIAS}

BRASIL. Lei $\mathrm{n}^{\circ}$ 9.394: Diretrizes e Bases da Educação Nacional. Disponível em: <http://www.planalto.gov.br/ccivil_03/leis/L9394.htm>. 20 de maio de 2015. Acesso em: 28 de Outubro de 2016.

BRASIL. Ministério da Educação. Programa Institucional de Iniciação à Docência. Disponível em: http://www.capes.gov.br/educacao-basica/capespibid/pibid. Acesso em 26 de Julho de 2016. (Para as portarias e decretos do PIBID).

BRASIL. Ministério da Educação. Programa Institucional de Iniciação à Docência. Disponível em: http://portal.mec.gov.br/pibid. Acesso em 26 de Julho de 2016.

BRASIL. Ministério da Educação. Programa Institucional de Iniciação à Docência. Disponível em <http://www.pibid.ufrn.br/>. Acesso em 28 de Julho de 2016.

BRASIL. PORTARIA No - 72, DE 9 DE ABRIL DE 2010. Dá nova redação a Portaria que dispõe sobre o Programa Institucional de Bolsa de Iniciação à Docência - PIBID, no âmbito da CAPES. Disponível em <https://www.capes.gov.br/images/stories/download/diversos/Portaria72_Pibid.pdf> Acesso em: Acesso em 04 de Agosto de 2016.

BRASIL. PORTARIA No 096, DE 18 DE JULHO DE 2013. Disponível em < http://www.capes.gov.br/images/stories/download/legislacao/Portaria_096_18jul13_AprovaR egulamentoPIBID.pdf $>$. Acesso em 04 de Agosto de 2016.

BRASIL. PORTARIA No 46, DE 11 DE ABRIL DE 2016. Aprova o Regulamento do Programa Institucional de Bolsa de Iniciação à Docência - Pibid. Disponível em < https:/www.capes.gov.br/images/stories/download/legislacao/15042016-Portaria-46-

Regulamento-PIBID-completa.pdf>. Acesso em 20 de Agosto de 2016.

BRASIL. PORTARIA NORMATIVA CAPES N 122 , DE 16 de setembro de 2009 Dispõe sobre o PIBID - Programa Institucional de Bolsa de Iniciação à Docência, no âmbito da CAPES. Disponível em <http://www.capes.gov.br/images/stories/download/bolsas/PortariaNormativa122_PIBID.pd> . Acesso em: Acesso em 04 de Agosto de 2016.

BRASIL. PORTARIA NORMATIVA Nº 38, DE 12 DE DEZEMBRO DE 2007. Dispõe sobre o Programa de Bolsa Institucional de Iniciação à Docência - PIBID. Disponível em $\langle$ http://www.cmconsultoria.com.br/imagens/diretorios/diretorio14/arquivo1003.pdf $>$. Acesso em: Acesso em 04 de Agosto de 2016.

BRASIL. RELATORIO DE GESTÃO/DEB 2009 A 2014. VOL I. CAPES. Disponível em < http://www.capes.gov.br/images/stories/download/bolsas/20150818 DEB-relatorio-de-gestaovol-1-com-anexos.pdf $>$. Acesso em 28 de Março de 2016.

BRASIL. RELATORIO DE GESTÃO/DEB 2013. CAPES. Disponível em $<$ https://www.capes.gov.br/images/stories/download/bolsas/2562014-relatrorio-DEB-2013web.pdf $>$. Acesso em 28 de Março de 2016. 
CANDAU, Vera Maria (org.). Reinventar a Escola. Petrópolis/RJ: Vozes, 2013.

FREIRE, Paulo. Pedagogia da Autonomia: Saberes necessários à prática educativa. Coleção Leitura. São Paulo: Paz e Terra, 1996.

MARX, Karl; ENGELS, Friedrich. A ideologia alemã. Tradução de José Carlos Bruni e Marco Aurélio Nogueira. São Paulo: Livraria Editora Ciências Humanas, 1998.

MORIN, Edgar. Os sete saberes necessários à educação do futuro. São Paulo: Cortez, 2004.

NOVOA, Antônio. Para uma formação de professores construída dentro da profissão. Revista Educacion. Madrid: 2009. .

OFÍCIO CIRCULAR FORPIBID No 01/2014. Aos Coordenadores Institucionais do Pibidhttp://pibid.cpdoc.fgv.br/sites/pibid.cpdoc.fgv.br/files/u27/oficio_forpibid_01-

2014_carta_de_natal.pdf. Acesso em 6 de agosto de 2016.

PROGRAMA INSTITUCIONAL DE BOLSAS DE INICIAÇÃO À DOCÊNCIA/ PIBIDUFRN. Relatórios Gerais. Disponível em 〈http://www.pibid.ufrn.br/>. Acesso em $15 \mathrm{de}$ Fevereiro de 2017.

SÁNCHEZ VÁZQUEZ, Adolfo. Filosofia da práxis. 2. ed. Rio de Janeiro: Paz e Terra, 1977. SANTOS, Boaventura Sousa. A universidade no século XXI. São Paulo: Cortez, 2004. 